\title{
sciendo
}

Transport and Telecommunication, 2019, volume 20, no. 2, 123-132

Transport and Telecommunication Institute, Lomonosova 1, Riga, LV-1019, Latvia

DOI 10.2478/ttj-2019-0011

\section{IDENTIFYING ROAD TRAFFIC ACCIDENTS HOTSPOTS AREAS USING GIS IN ETHIOPIA: A CASE STUDY OF HOSANNA TOWN}

\author{
Temesgen Haile Hayidso ${ }^{1}$, Dessalegn Obsi Gemeda ${ }^{2}$, Ashenif Melese Abraham ${ }^{3}$ \\ ${ }^{1}$ Southern Nations, Nationalities, and Peoples' Region (SNNPR), Hadiya Zone, \\ Hosanna Town Transport Authority, Hosanna, Ethiopia, \\ adinewhayidso2009@gmail.com \\ ${ }^{2}$ Jimma University College of Agriculture and Veterinary Medicine, Department of Natural Resources \\ Management, Jimma, Ethiopia, \\ dasoobsi@gmail.com / dessalegn.obsi@ju.edu.et \\ ${ }^{3}$ Jimma University College of Social Science and Humanities, Department of Geography and \\ Environmental Studies, Jimma, Ethiopia, \\ ashenifmelese7@gmail.com
}

\begin{abstract}
Due to increasing human population and the number of vehicles, road traffic accident has significant influence on human life and economic development. In the present study, road traffic accident data of three years (2015-2017) were obtained from Hosanna Town Traffic Police Department, and Hosanna Town Transport Authority in Ethiopia. The Global Position System was used to know X, Y coordinates of the accident locations. Global Position System point data and accident data were added to road network data using the 'Joins and relates' function in ArcGIS. The results of the study showed a total of 241 Road traffic accidents (RTAs) were occurred in the town from which about 208 victims occurred on people and 33 damaged properties. Based on severity and frequencies of RTAs top nine hot spot areas were identified which requires high attention to protect people and property from damage and loss. Thus, the government and other concerned stakeholders should provide public education and awareness creation to reduce risk of fatalities and property damage due to RTAs in Hosanna town.
\end{abstract}

Keywords: GIS, GPS, Hotspots, Road Traffic Accidents, Spatial distribution

\section{Introduction}

Road traffic accidents (RTAs) are one of the serious problems at the global level that results in loss of life and economic damage. Road accident fatalities and injuries are increasing all over the world (Aghajani et al., 2017). Due to RTAs about 1.3 million people lose their life, between 20-50 million people disabled and about 518 billion US\$ lost annually at global level (Hordofa et al., 2018). Dereli and Erdogan (2017) concluded that a traffic accident is a serious problem that threatens human life. Estimation of death-related losses normally includes social, and economical losses (Karpova and Julmukhamedova, 2017). Road traffic accidents lead to a large number of fatal incapacitating injuries; the consequences of these accidents are fundamentally reflected in the social sphere (Kontakt, 2017). The RTAs are increasing at global level due to the development of transportation infrastructure fails to keep pace with other sectors (Shafabakhsh et al., 2017). The road accidents are mostly the results of three factors, namely, human factors, vehicle factors, and external factors like road conditions (Aghajani et al., 2017; Soehodho, 2017). Another study conducted by Gicquel et al. (2017) identifies the use cell phone while driving, and attention deficit disorder with or without hyperactivity is another risk factors for traffic accidents. Mobile phone use while driving was a significant distraction, especially in young drivers, that impaired driving performance, thus becoming a leading cause of traffic accidents (Kountouriotis and Merat, 2016).

Several studies (Elliott et al., 2009; Stübig et al., 2012; Callaghan et al., 2013; Yang et al., 2013; Bogstrand et al., 2015; AL-Abdallat et al., 2016; Costa et al., 2012; Ferrari et al., 2018) confirmed that there is a close relationship between alcohol abuse and the risk of vehicle accidents. Waylen and McKenna (2008) and Gicquel et al. (2017) found that alcohol greatly increased the probability of having a car accident and the severity of its consequences. As reported by Stübig et al. (2012), alcohol is one of the most important personal risk factors for serious and fatal injuries, contributing to approximately one third of all deaths from accidents. The results obtained by Bogstrand et al. (2015) indicates that the majority of the drivers with a 
fatal outcome in road traffic crashes who were impaired by alcohol or drugs, unbelted or had speeded. Similar to alcohol use and speed factors, vehicle factors are also contributing to the occurrence of traffic accidents. Technical requirements for vehicles and their parts significant changes occur constantly, mainly due to the progressive technological developments and thus, every vehicle operated on the road has to be approved (Liscak and Moravcik, 2013). Vehicles, technical system such as design, lighting system, and brake system and service age are significant contributors to RTAs (Dowing et al., 1999). The vehicle technical quality of developing countries is lower than developed countries. Worn out vehicles are more likely to be involved in traffic accidents. Vehicles with seat belts, adequate lights, brakes, and good steering wheel, can minimize RTAs.

When we compare with developed nations, the middle-income countries had the highest fatality rates, but when adjusted for the number of motor vehicles, the poorest countries showed the highest road traffic fatality rates (Wiebe et al., 2016). African countries had the highest mortality, which is about 28.3 deaths per 100,000 population (Admassie et al., 2010). Africa Development Bank of 2013 reports indicates the about $65 \%$ road users are vulnerable to road crash victims in Africa continent. Pedestrians are vulnerable road users, which are very susceptible to RTAs (Galanis et al., 2017). In Africa, the number of road traffic injuries and deaths has been increasing over the last three decades. An increasing economic trend of an individual increases the number of cars and the existing infrastructure unable to accommodate, which will lead to traffic accidents (Lizbetin and Bartuska, 2017). Africa takes the highest share of the road crash burden relative to its low level of motorization and road network density (Adeloye et al., 2016). In African countries, deaths from road traffic injuries are $40 \%$ higher than in all other low and middle income countries (Hailemichae et al., 2015).

Various authors have been used Geographic information science (GIS) technology (Deepthi and Ganeshkumar, 2010; Qian et al., 2012; Gomes, 2012; Dereli and Erdogan, 2017, Aghajani et al., 2017) for spatial and temporal patterns of RTAs identification. The GIS technology has the capacity to indicate the precise location of the traffic accident data, which can be determined by the coordination of the scene of the accident (Dereli and Erdogan, 2017). Moreover, query can be easily performed, enhanced by graphical representation. Road characteristics, roadway features, and user characteristics are some of the major factors for identification of accident-prone areas through GIS technology (Kamalasudhan et al., 2009). Urban planner focused on improving road use of vehicles, while neglecting the needs of the most vulnerable road users are pedestrians (Mandar et al., 2017). Because of the frequent occurrences of traffic accidents, there is a growing concern in traffic accident rate in recent years. Ethiopia has a very low road network density and vehicle ownership as compared with other African countries; inversely the country has recorded high RTAs (Hailemichael et al., 2015). The main objective of this study is to analysis and ranking the RTAs hotspot in Hosanna Town.

\section{Materials and Methods}

\subsection{Description of study area}

Hosanna is administrative Town of Hadiya zone and found in South Nation, Nationalities and Peoples Regional State of Ethiopia, and geographically located at about 232 kilometres south from the capital Addis Ababa, $168 \mathrm{~km}$ away from Hawassa, and $89 \mathrm{kms}$ away from Butajira (Fig. 1). Hosanna is found at $7^{\circ} 30^{\prime} 30^{\prime \prime} \mathrm{N}-7^{\circ} 35^{\prime} 30^{\prime \prime} \mathrm{N}$ latitude and $37^{\circ} 48^{\prime} 30^{\prime \prime} \mathrm{E}-37^{\circ} 54^{\prime} 30^{\prime \prime} \mathrm{E}$ longitudes.

\subsection{Data and methods}

Several data sources were used to assess the extent of RTAs in Hosanna town. A cross -sectional study was conducted using road traffic accident data records of three years (2015-2017) from Hadiya Zone and Hosanna Town Traffic Police Department, Hadiya Zone and Hosanna Town Transport Authority. Both quantitative and qualitative research techniques were employed to collect data through key informant interviews and focused group discussions (FGDs). In data collections, total number of people involved in the accident, total number of vehicles involved in the accidents, number of accidents, nature of accidents include (fatality, injury and property damage), time and location of accident occurrence were included. Global Position System (GPS) data were collected to determine the location of RTAs in the study area. 


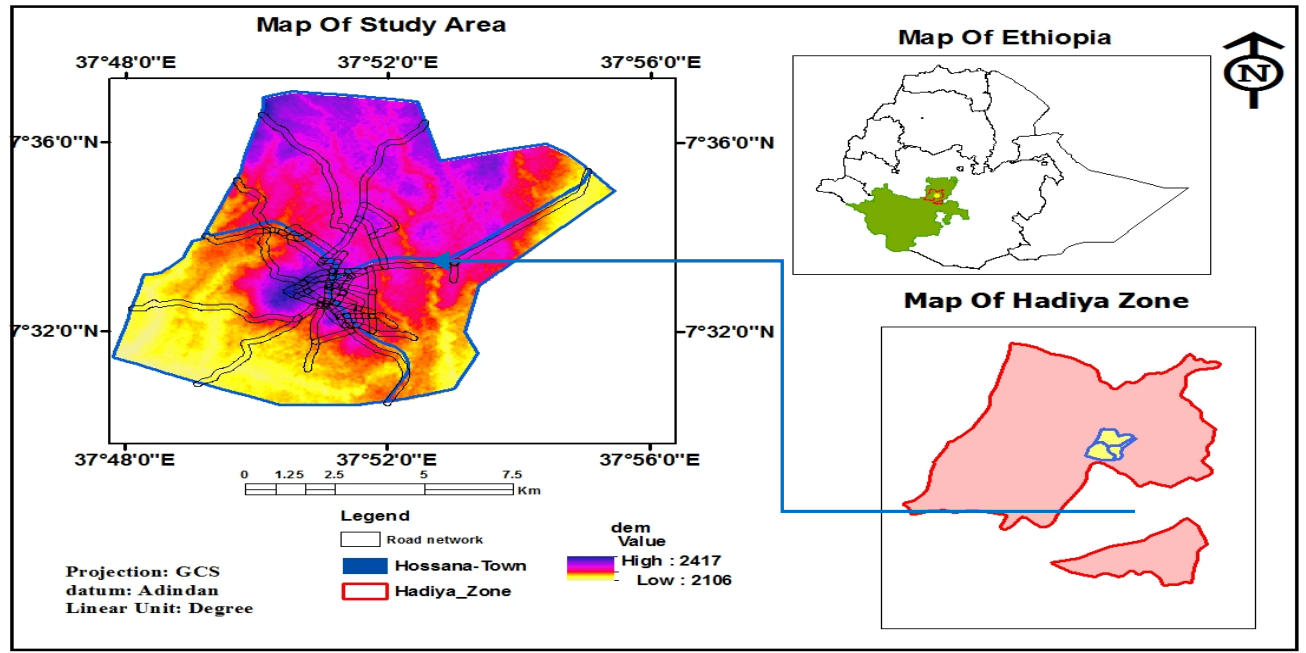

Figure 1. Map of the study area

After GPS surveyed all accident data were Geocoded with its accident locations by using code number and location name in Excel for spatial analysis. Geocoded RTAs data of Hosanna Town were exported into ArcGIS 10.3 as a point shape file. Google Earth was also used for extracts road data of the town, field observation to check road design of accident, interviewed with key informants and FGDs to know the magnitude of RTAs in town and to gather solution ideas. The RTAs hotspots ranking processes were undergo by investigating the past three years accident data. And finally, with the help of a "Join" function in ArcGIS, and GPS point data was automatically combine with RTAs in order to prioritize RTAs hotspots area following Geurts and Wets (2003) ranking schemes by using the following formula:

$\mathrm{S}=\mathrm{X}+3 \mathrm{Y}+5 \mathrm{Z}$

where:

$\mathrm{S}=$ severity,

$\mathrm{X}=$ total number of minor injuries within each RTAs hotspot,

$\mathrm{Y}=$ total number of major injuries within each RTAs hotspot, and

$\mathrm{Z}=$ total number of fatalities within each RTAs hotspot.

\section{Results and Discussions}

\subsection{Drivers related factors}

Driver factors are depend on the individuals unique characteristics like age, sex, education and training level, as well as the living environment has an impact on the occurrence of RTAs. The driver's age and educational levels are fundamental factor for occurrence of RTAs. The traffic Police data of Hosanna town showed that, younger age (18-50) drivers were more frequently involved in RTAs than adult and old aged $(>51)$ years (Table 1$)$. The young drivers with an age from (18-30) are the most vulnerable, which results a total record of 122 accidents $(50.6 \%)$ within only three years. This is mainly due to the fact that the adolescent's age groups are risk taking behaviour and have low driving experience. Age from (31-50) were the second most susceptible groups, they hold about $20 \%$ of road accidents.

Table 1. Drivers age distributions in RTAs

\begin{tabular}{|l|l|l|l|l|l|}
\hline Age & $\mathbf{2 0 1 5}$ & $\mathbf{2 0 1 6}$ & $\mathbf{2 0 1 7}$ & Total & \% \\
\hline$>18$ & 3 & 5 & 3 & 11 & $4.6 \%$ \\
\hline $18-30$ & 28 & 43 & 51 & 122 & $50.6 \%$ \\
\hline $31-50$ & 12 & 17 & 20 & 49 & $20.3 \%$ \\
\hline$<50$ & 2 & 5 & 6 & 13 & $5.4 \%$ \\
\hline Unknowns & 7 & 23 & 16 & 46 & $19 \%$ \\
\hline Total & 52 & 93 & 96 & 241 & $100 \%$ \\
\hline
\end{tabular}

Source: Hosanna town traffic police department 
Because most young age (18-50) drivers are characterized by high speed, low driving experience and driving with over confidence. Parallel to age category, educational level also makes a great variation on the occurrences of RTAs. This is illustrated in Table 2, drivers who completed elementary school and junior high school were more repeatedly involved in RTAs than those completed high school and above educational level. For instance, drivers who completed elementary school and junior high school were the most susceptible to RTAs which contain 79 (32.8\%) and $56(23.2 \%)$ respectively. While high school and above high school education level drivers were contributed $14 \%$ and $6.2 \%$ RTAs respectively. Thus, we can conclude that the more educated drivers were less record while the less educated and those writing and reading skills have more participate in RTAs.

Table 2. Drivers' educational levels and people victims by RTAs

\begin{tabular}{|l|l|l|l|l|l|}
\hline Educational level & $\mathbf{2 0 1 5}$ & $\mathbf{2 0 1 6}$ & $\mathbf{2 0 1 7}$ & Total & \% \\
\hline Illiterate & 0 & 0 & 0 & 0 & 0 \\
\hline Writing \& reading & 7 & 18 & 15 & 40 & $16.6 \%$ \\
\hline Elementary school & 17 & 29 & 33 & 79 & $32.8 \%$ \\
\hline Junior high school & 12 & 19 & 25 & 56 & $23.2 \%$ \\
\hline High school & 7 & 14 & 13 & 34 & $14 \%$ \\
\hline Above high school & 3 & 6 & 6 & 4 & $6.2 \%$ \\
\hline Unknown & 6 & 7 & 96 & 241 & $7 \%$ \\
\hline Total & 52 & 93 & & $100 \%$ \\
\hline
\end{tabular}

Source: Hosanna town traffic police department

\subsection{Pedestrian related factors}

The pedestrian characteristics such as road crossing behaviour, job status, gender, age, and education levels play an important role in RTAs in Hosanna town. As we collect information through key informants and FGDs, as well as Hosanna traffic police department indicates that the insecure crossing behaviour of road was one of the main causes of traffic accidents in the study area. Galanis et al. (2017) has also found that, pedestrian are vulnerable road users due to their expose to high risk level during their interaction with fast motorized traffic. In total about 134 RTAs occurred on pedestrian in past three years at different road segments. With regard to gender, in Hosanna town casualty of male statistics shows a big difference from female. Male are far more likely to be killed or seriously injured on roads (73\%) than women; the same is true for other Africa countries (WHO, 2013).

\subsection{Distribution of RTAs over week}

In the investigated three year period annually an average of 80 car accidents occurred in the study area. Of these accidents, $65(27 \%)$ were occurring on Saturday, $41(19.5 \%)$ and $40(16.6 \%)$ were happening on Tuesday and Sunday respectively (Table 3). The assumed primary reason for the high number of TRAs on Saturday and Tuesday associated with the presence of market day, high congestion of people and vehicle. The mobility of people and vehicles are varying from day to day depend on local economic and social activity. As reported by Lizbetin and Bartuska (2017), with increasing economic development of individual states, the number of cars is increasing and the existing road infrastructure unable to accommodate, which will lead to traffic accidents. The total number of accidents occurred over the years are increasing. The frequency of road crashes on Saturday was extremely higher than other days over a week. The frequency of RTAs on Sunday is also high, 40 (16.6\%), several people spend on recreation and sometimes more drivers and pedestrian impaired with alcohol. The remaining accident occurred in ordinary days, $22(9 \%)$ on Monday, $12.8 \%$ on Friday, $9 \%$ on Thursday and $8.3 \%$ on Wednesday.

\subsection{Road traffic accidents peak time}

The RTA can vary within the 24 hours of a day. The environmental factors like the availability of light, the congestion of vehicles and the number of pedestrians vary within 24 hours of the day. There is a direct correlation between traffic accident and vehicle congestion. Formation of congestion is closely related to the density of traffic over the road which is mostly occurred starting from the morning to early afternoon when the demand for transport is very high. Figure 2 shows the traffic peak time starts at noon and slightly increased until the midnight (12:00pm). 
Table 3. Distributions of RTAs over week

\begin{tabular}{|l|l|l|l|l|l|}
\hline \multirow{2}{*}{ Days of weeks } & \multicolumn{3}{|c|}{ Accident years } & \multirow{2}{*}{ Total } & \multirow{2}{*}{ Percent \% } \\
\cline { 2 - 6 } & $\mathbf{2 0 1 5}$ & $\mathbf{2 0 1 6}$ & 5 & $\mathbf{2 0 1 7}$ & \\
\hline Monday & 8 & 17 & 15 & 22 & 9 \\
\hline Tuesday & 9 & 9 & 6 & $\mathbf{4 1}$ & $\mathbf{1 9 . 5}$ \\
\hline Wednesday & 5 & 6 & 12 & 20 & 8.3 \\
\hline Thursday & 4 & 8 & 13 & 31 & 9 \\
\hline Friday & 10 & 26 & 27 & $\mathbf{6 5}$ & 12.8 \\
\hline Saturday & 12 & 20 & 96 & $\mathbf{4 0}$ & 271 \\
\hline Sunday & 5 & 93 & $\mathbf{1 6 . 6}$ & 100 \\
\hline Total & 52 & & & 241 \\
\hline
\end{tabular}

Source: Hosanna town traffic police department.

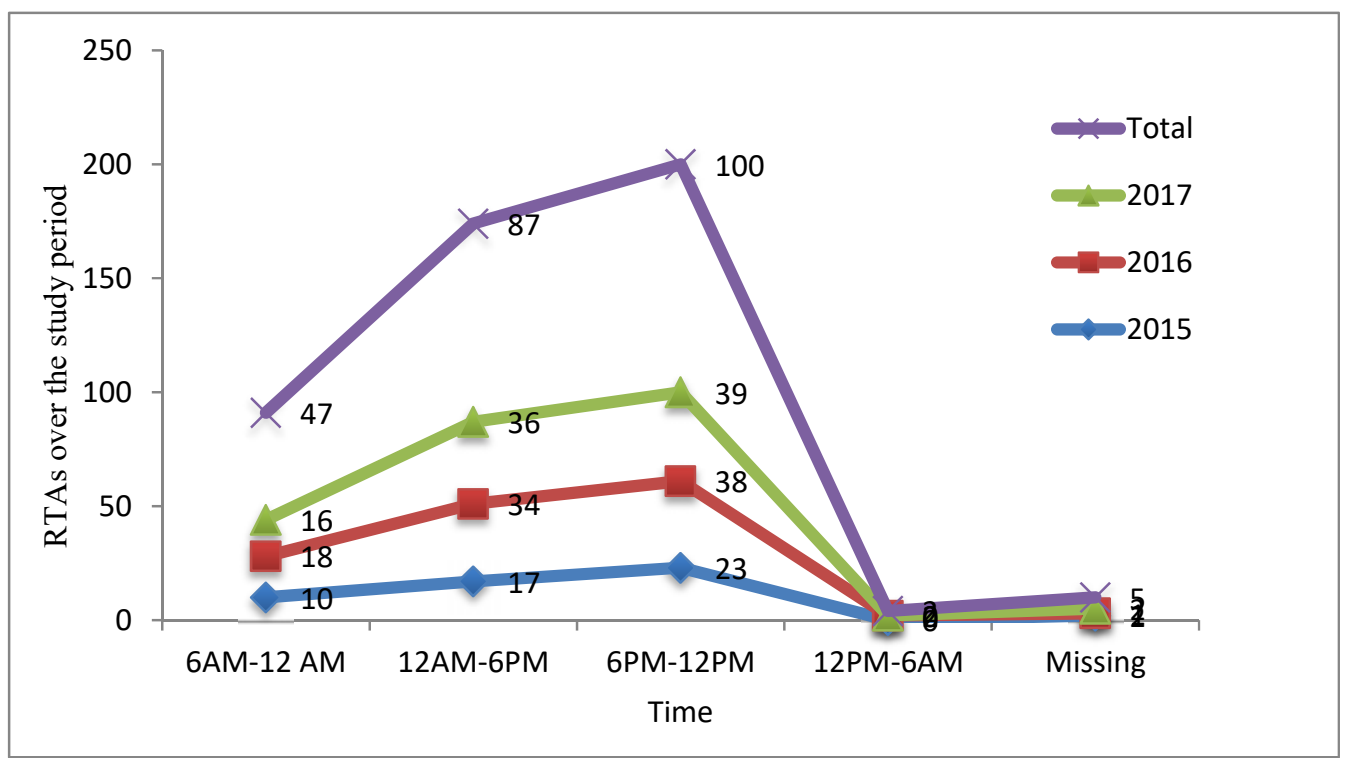

Figure 2. Distribution of RTAs along time events (Source: Hosanna town traffic police department)

As shown in Figure 2, most severs time for RTAs in Hosanna town was 6PM-12PM which shares $100(41.5 \%)$ out of 241 RTAs. At this moment, most urban and rural residential return back to their home and creates congestion of vehicle and pedestrian. The second most serious time was during the day time from 6AM-6PM which shares $87(36 \%)$ out of total accidents. Relatively lower accidents $47(19.5 \%)$ occurred between 6AM-12AM, no more congestion in the town at this time. From 12PM- 6AM, very low accidents occurred in the town.

\subsection{Negative effects of RTAs}

Road traffic accidents have negative effects on a particular country due to personal injuries and property damage which costs high amount of capital for rehabilitation. Similar to other countries, traffic accidents are one of the serious problems that destroy people life and properties. From 2015 to 2017, 241 RTAs were registered in Hosanna town, of which 208 individuals were affected by these accidents. Among the accidents, 62 resulted in death, 146 caused injuries and 33 accident damaged property (Table 4). Fatalities and injuries resulting from RTAs are major public health problems in Ethiopia. There has been an alarming increase in accidental deaths in Hosanna town. Road accidental fatalities have increased from 13 people in 2015 to 25 in 2017. Property costs due to traffic accidents have been a serious issue in Ethiopia. Moreover, the occurrence of RTAs in the study area is increasing from time to time. For instance, in 2015 the total number of accidents were 52 (22\%) increased to 93 in 2016 (38.8\%), which indicates an increasing trend with $15.7 \%$ from 2015, and in 2017 total accident was reached 95 (39.4\%), by increasing to $1.4 \%$ from 2016. In general, the number of RTAs was increased from time to time both 
in life loss and property destruction. Fatalities of traffic accidents were steadily increasing in the studies of three fiscal years.

Table 4. Number and type of RTAs in Hosanna town from 2015-2017

\begin{tabular}{|l|l|l|l|l|l|l|l|l|l|}
\hline Year & \multicolumn{3}{|l}{ Fatality } & \multicolumn{2}{l|}{ Injure } & & $\begin{array}{l}\text { Property } \\
\text { damage }\end{array}$ & Sum & Overall \% \\
\hline & + & - & Total & + & - & Total & & & \\
\hline 2015 & 10 & 3 & 13 & 21 & 9 & 30 & 9 & 52 & $22 \%$ \\
\hline 2016 & 15 & 9 & 24 & 37 & 21 & 58 & 11 & 93 & $37.7 \%$ \\
\hline 2017 & 17 & 8 & 25 & 38 & 20 & 58 & 13 & 96 & $40.3 \%$ \\
\hline Total & 42 & 20 & 62 & 96 & 50 & 146 & 33 & 241 & $100 \%$ \\
\hline
\end{tabular}

+ Male, - Female

In addition to life loos, RTAs have hug impacts on the economy of a country. Table 5 shows a magnitude of RTAs on economy of town along with estimated cost from 2015 to 2017 years in Hosanna town.

Table 5. Economic impacts of RTAs in Hosanna town from 2015-2017

\begin{tabular}{|l|l|l|l|}
\hline Accident & No property damage & Estimated cost (ETB) & \% \\
\hline 2015 & 9 & $1,763,4000$ & $41.5 \%$ \\
\hline 2016 & 11 & 685,000 & $15.9 \%$ \\
\hline 2017 & 13 & $1,647,378$ & $38.5 \%$ \\
\hline Total & 33 & 4295778 & $100 \%$ \\
\hline
\end{tabular}

Source: Hosanna town traffic police department

\subsection{Road traffic accidents hotspots areas}

Road traffic accidents hotspots are determined by the support of GIS technology. The geographic location and coordinate information about the traffic accidents may provide more detailed information compared to traditional statistical analysis methods (Yang et al., 2013). In 2015, the RTAs hotspot site map showed that, the highest frequency was recorded in Addis-Ketema sub-town which was happening because of high vehicle congestion since most of governmental and nongovernmental institution, schools, and hotels are found in this sub-town (Fig. 3). Sech Duna and Gofermeda sub-town shows relatively lower RTAs than Addis-Ketema sub-town. The highest frequency (5) of RTAs was recorded around Ashame Hotel in Addis-Ketema sub-tow mainly due to the existences of business centre and a lot of pedestrian and vehicle congestion.

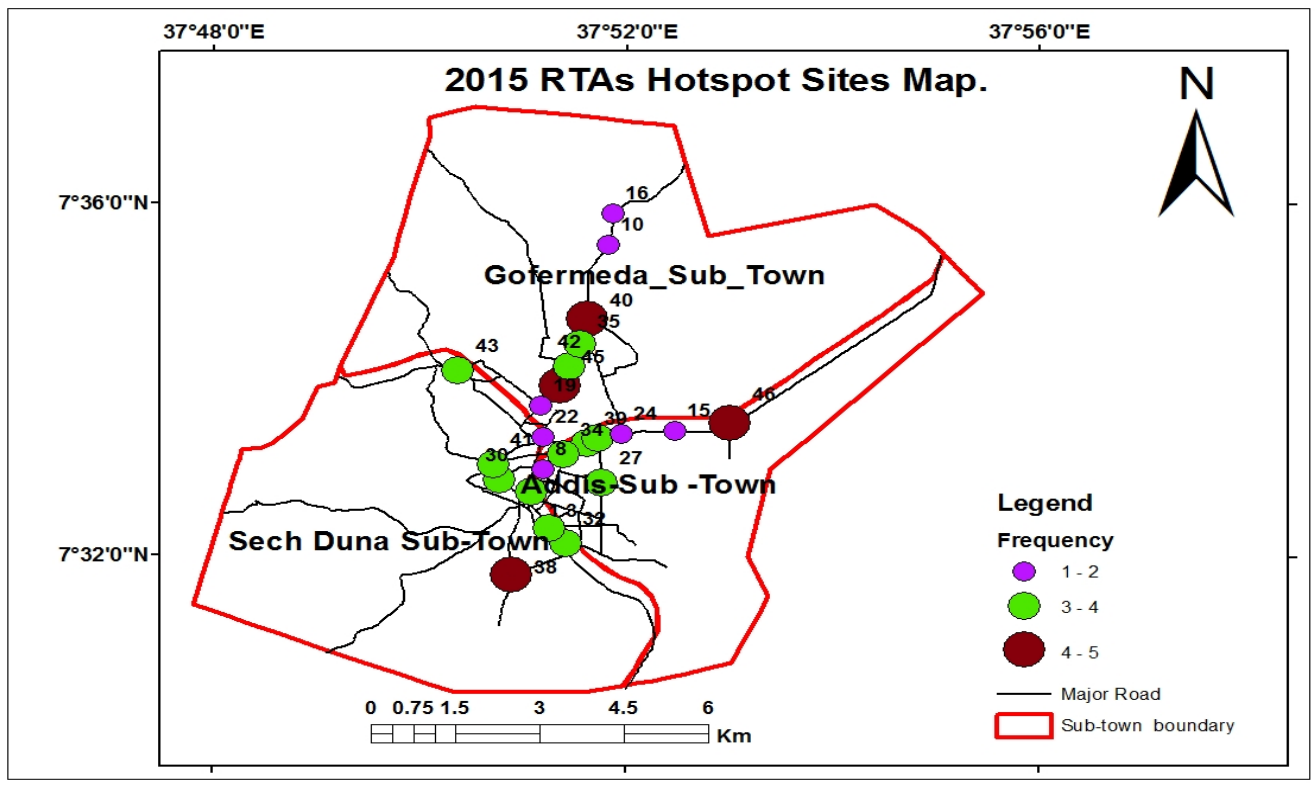

Figure 3. Spatial distributions and frequency of RTAs Hotspots areas in 2015 
In 2016, the highest RTAs frequency was occurred in in front of Wachamo University and Colonel Bezabeh Petros square (Fig. 4). The RTAs hotspot areas of 2016 were demonstrated in Figure 4. Because in front of Wachamo University, there is other y junction road and the road itself is a two way road (i.e. vehicle moves from the opposite direction in one single road) and the road is steep sloped and no speed breaker. On Colonel Bezabih Petros square road there were different types of vehicle and pedestrian congestions, since it is the main route to and from the town bus station. Besides, the absence of traffic light, traffic signs, visibility and pedestrian crossing line (Zebera) accelerates the problem of RTAs in this area. The number of hotspots and RTAs frequency varies across the town. Similar to 2016, several RTAs were occurring in 2017 in Hosanna town (Fig. 5).

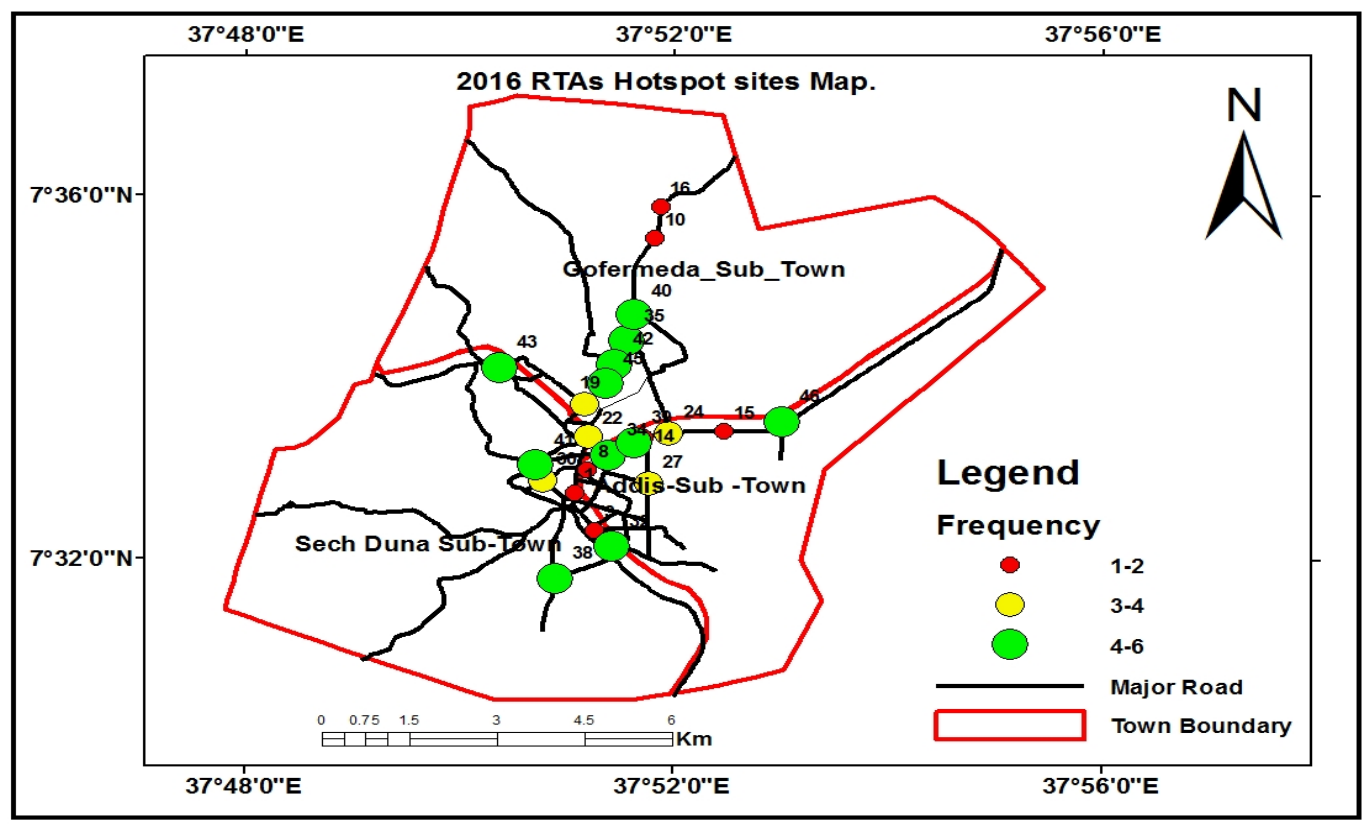

Figure 4. Spatial distribution and frequency of RTAs in 2016

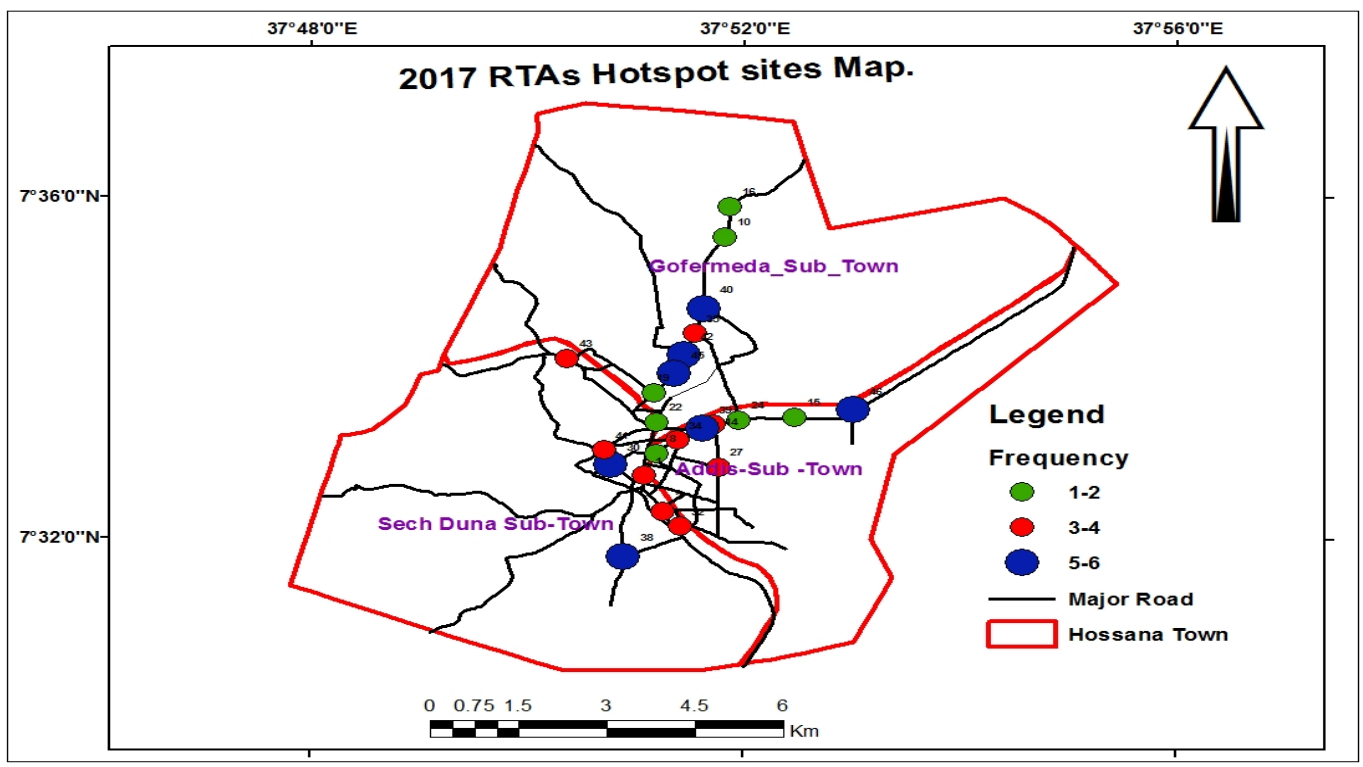

Figure 5. Spatial distribution and frequency of RTAs in 2017 


\subsection{Top nine RTAs hotspots areas in Hosanna town}

As shown in Table 6, Wachamo University, St. Mary Church and around Colonel Bezabih Petros square were ranked $1^{\text {st }}, 2^{\text {nd }}$ and $3^{\text {rd }}$ respectively in RTAs in Hosanna town. Wachamo University road is the main get an outlet in Southern Ethiopia, capital city, Addis Ababa and Oromia National Regional State, which makes high vehicle congestion. In addition to vehicle, there are congested pedestrian, particularly university student and other road use. The St. Mary Church is located near to Saturday and Tuesday market place of Hosanna and most of the time the road crowded with pedestrian and vehicles. Moreover, the y shape road junction, one way road facilities, lack of visible road signs and traffic light contributes for the frequent occurrences of RTAs in this area. The other key RTAs hotspots are around the Colonel Bezabeh Petros square, which is located near to the bus station, and the main route to and from many directions to bus station. In this area, no pedestrian crossing zebra, existences of banks, hotels and other facilities enhance congestion of people and vehicles.

Table 6. Top nine RTAs Hotspots areas with Severity Value

\begin{tabular}{|l|l|c|l|l|}
\hline Code & Name of Hotspot & Number of RTAs & Severity Value & Rank \\
\hline 46 & In front of Wachamo University & 13 & 39 & 1 \\
\hline 39 & In front of St. Mary Church & 10 & 26 & 2 \\
\hline 30 & Colonel Bezabih Petros square & 7 & 25 & 3 \\
\hline 08 & In front of Nigist Elaine Referral Hospital & 8 & 24 & 4 \\
\hline 40 & TTC Mazoria & 8 & 20 & 6 \\
\hline 14 & In front of Hosanna electric Substation & 8 & 19 & 7 \\
\hline 01 & In front of 25/67 School & 6 & 18 & 8 \\
\hline 38 & Soro Bar & 8 & 14 & 9 \\
\hline 22 & Iyerusalem Square & 7 & \\
\hline
\end{tabular}

\section{Conclusion and Future Work}

In this paper, the occurrences and frequencies of RTAs in Hosanna town have been discussed. The data were collected from Hosanna town traffic police department and Hosanna town transport authority. Geographic Information Science and Global positioning System were also employed for mapping the spatial distribution of RTAs Hotspots over the study period. The Global positioning System is often used to visualize the distribution and frequency of RTAs hotspot areas by using ArcGIS software.

To minimize the frequency and occurrences of RTAs in the study area the concerned stakeholders should create awareness creations on the negative impacts of RTAs on an individual's life and country economic development. Policy enforcements are required on the effects of over loading, over speed, mobile conversation and use of alcohol during driving. The traffic police department and other relevant sectors will follow up the technical quality of vehicles, vehicle service years, traffic jam, road infrastructure such as visible zebra, separation and road traffic light, and traffic law enforcement to minimize the risks of fatalities and property damage. The last, not the least, providing effective and affordable public transportation services is very crucial in order to reduce the frequency of RTAs in Hosanna town.

\section{Acknowledgements}

The authors would like to thanks Jimma University College of Social Sciences and Humanities, Department of Geography and Environmental Studies for providing research fund and Jimma University College of Agriculture and Veterinary Medicine, Department of Natural Resources Management for the existing facilities to download necessary supporting materials particularly scientific documents.

\section{References}

1. Adeloye, D., Thompson, J.Y., Akanbi, M.A., Zzuh, D., Samuel, V., Omoregbe, N. and Ayo, C.K. (2016) Bulletin of the World Health Organization. The burden of road traffic crashes, injuries and deaths in Africa: a systematic review and meta-analysis. -

http://www.who.int/bulletin/volumes/94/7/15-163121/en/ (Accessed on November 6, 2018). 
2. Admassie, A., Yirga, T. and Wamisho, B.L. (2010) Adult limb fractures in Tikur Anbessa hospital caused by road traffic injuries: half year plain radiographic pattern. Ethiop. J Health Dev, 24 (1), 6163. DOI: 10.4314/ejhd.v24i1.65716.

3. Africa Development Bank Group (2013) Road Safety in Africa Assessment of Progresses and Challenges in Road Safety Management System. Transport and ICT Department, December 2013. www.afdb.org.

4. Aghajani, M.A., Dezfoulian, R.S., Arjroody, A.R. and Rezaei, M. (2017) Applying GIS to Identify the Spatial and Temporal Patterns of Road Accidents Using Spatial Statistics (Case study: Ilam Province, Iran). World Conference on Transport Research-WCTR 2016 Shanghai. 10-15 July 2016. Transportation Research Procedia, 25, 2126-2138. DOI: 10.1016/j.trpro.2017.05.409.

5. Al-Abdallat, I.M., Ali, R.A., Hudaib, A.A., Salameh, G.A.M., Salameh, R.J.M. and Idhair, A.K.F. (2016) The prevalence of alcohol and psychotropic drugs in fatalities of road-traffic accidents in Jordan during 2008-2014. Journal of Forensic and Legal Medicine, 39, 130-134. DOI: 10.1016/j.jflm.2016.01.018.

6. Bogstrand, S.T., Larsson, M., Holtan, A., Staff, T.,Vindenes, V. and Gjerde, H. (2015) Associations between driving under the influence of alcohol or drugs, speeding and seatbelt use among fatally injured car drivers in Norway. Accident Analysis and Prevention, 78, 14-19. DOI: 10.1016/j.aap.2014.12.025.

7. Callaghan, R.C., Gatley, J.M., Veldhuizen, S., Lev-Ran, S., Mann, R. and Asbridge, M. (2013) Alcohol- or drug-use disorders and motor vehicle accident mortality: A retrospective cohort study. Accident Analysis and Prevention, 53, 149-155. DOI: 10.1016/j.aap.2013.01.008.

8. Costa, N., Silva, Mendonca, M.C., Real, F.C., Vieira, D.N. and Teixeira, H.M. (2012) Prevalence of ethanol and illicit drugs in road traffic accidents in the centre of Portugal: An eighteen-year update. Forensic Science International, 2016, 37-43. DOI: 10.1016/j.forsciint.2011.08.013.

9. Deepthi, J.K. and Ganeshkumar, B. (2010) Identification of Accident Hot Spots: A GIS Based Implementation for Kannur District, Kerala. International Journal of Geometrics and Geosciences, 1(1), 51-59. ISSN 0976-4380.

10. Dereli, M.A. and Erdogan, S. (2017) A new model for determining the traffic accident black spots using GIS-aided spatial statistical methods. Transportation Research Part A, 103, 106-117: http://dx.doi.org/10.1016/j.tra.2017.05.031.

11. Dowing, A. J., Baguley, C. J. and Hills, B. (1999) Road Safety in Developing Countries: An overview. Oversees Centre. Transport and Road Research Laboratory, Crowthorne, Berkshire, United Kingdom.

12. Elliott, S., Woolacott, H. and Braithwaite, R. (2009) The prevalence of drugs and alcohol found in road traffic fatalities: A comparative study of victims. Science and Justice, 49, 19-23. DOI: 10.1016/j.scijus.2008.06.001.

13. Ferrari, D., Manca, M., Banfi, G. and Locatelli, M. (2018) Alcohol and illicit drugs in drivers involved in road traffic crashes in the Milan area. A comparison with normal traffic reveals the possible inadequacy of current cut-off limits. Forensic Science International, 282,127-132. DOI: 10.1016/j.forsciint.2017.11.005.

14. Galanis, A., Botzoris, G. and Eliou, N. (2017) Pedestrian road safety in relation to urban road type and traffic flow. 3rd Conference on Sustainable Urban Mobility, 3rd CSUM 2016, 26-27 May 2016, Volos, Greece. Transportation Research Procedia, 24,220-227. DOI: 10.1016/j.trpro.2017.05.111.

15. Geurts, K. and Wets, G. (2003) Black Spot Analysis Methods: Literature Review.

16. Gicquel, L., Ordonneau, P., Blot, E., Toillon, C., Ingrand, P. and Romo, L. (2017) Description of Various Factors Contributing to Traffic Accidents in Youth and Measures Proposed to Alleviate Recurrence. Front Psychiatry, 8, 94. DOI: 10.3389/fpsyt.2017.00094.

17. Gomes, S.V. (2012) The influence of the infrastructure characteristics in urban road accidents occurrence. Procedia-Social and Behavioral Sciences, 48, 1611-1621. DOI: 10.1016/j.sbspro.2012.06.1136.

18. Hailemichael, F., Suleiman, M. and Paulo's, W. (2015) Magnitude and outcomes of road traffic accidents at Hospitals in Wolaita Zone, SNNPR, Ethiopia. BMC Res Notes, 8(1), 135. DOI: 10.1186/s13104-015-1094-Z.

19. Hordofa, G.G., Assegid, S., Girma, A. and Weldemarium, T.D. (2018) Prevalence of fatality and associated factors of road traffic accidents among victims reported to Burayu town police stations, between 2010 and 2015, Ethiopia. Journal of Transport and Health. 10, 186-193. DOI: 10.1016/j.jth.2018.06.007. 
20. Hossana Police Office (2017). Annual Traffic Report. Hosanna Traffic Police statistic accident data. Unpublished document.

21. Kamalasudhan, A., Mitra, S., Huang, B.O. and Chin, H.C. (2009) An analysis of expressway Accidents in Singapore, Department of Civil Engineering, National University of Singapore, Singapore.

22. Karpova, G. and Julmukhamedova, G. (2017) Modes for Estimating Human Capital Losses due to Traffic Related Deaths. 12th International Conference "Organization and Traffic Safety Management in large cities", SPbOTSIC-2016, 28-30 September 2016, St. Petersburg, Russia. Transportation Research Procedia, 20, 267 - 271. DOI: 10.1016/j.trpro.2017.01.016.

23. Kontakt, M. (2017) Health and social consequences of road traffic accidents. University of South Bohemia in České Budějovice, Faculty of Health and Social Sciences, Department of Radiology, Toxicology and Civil Protection, České Budějovice, Czech Republic. DOI: 10.1016/j.kontakt.2017.01.007 (Accessed on November 9, 2018).

24. Kountouriotis, G.K. and Merat, N. (2016) Leading to distraction: Driver distraction, lead car, and road environment. Accident Analysis and Prevention, 89, 22-30. DOI: 10.1016/j.aap.2015.12.027.

25. Liscak, S. and Moravcik, L. (2013) Safety requirements for road vehicles.4 (8).

26. Lizbetin, J. and Bartuska, L. (2017) The Influence of Human Factor on Congestion Formation on Urban Roads. 10th International Scientific Conference Transbaltica 2017: Transportation Science and Technology. Procedia Engineering, 187, 206-211. DOI: 10.1016/j.proeng.2017.04.366.

27. Mandar, M., Boulmakoul, A. and Lbath, A. (2017) Pedestrian fuzzy risk exposure indicator. 19th EURO Working Group on Transportation Meeting, EWGT2016, 5-7 September 2016, Istanbul, Turkey. Transportation Research Procedia, 22, 124-133. DOI: 10.1016/j.trpro.2017.03.019.

28. Qian,Y.U., Juncheng, J., Hanhua,YU. (2012) Research on the emergency response system of major dangerous chemical accident on highway based on the GIS. 2012 International Symposium on Safety Science \& Technology. Procedia Engineering, 45, 716-721. DOI: 10.1016/j.proeng.2012.08.229.

29. Shafabakhsh, G., Famili, A. and Bahadori, M.S. (2017) GIS-based spatial analysis of urban traffic accidents: Case study in Mashhad, Iran. Journal of Traffic and Transportation Engineering, 4 (3), 290-299. DOI: 10.1016/j.jtte.2017.05.005.

30. Soehodho, S. (2017) Public transportation development and traffic accident prevention in Indonesia. IATSS Research, 40, 76-80. DOI: 10.10.16/j.iatssr.2016.05.001.

31. Stübig, T., Petri, M., Zeckey, C., Brand, S., Muller, C., Otte, D., Krettek, C. and Haasper, C. (2012) Alcohol intoxication in road traffic accidents leads to higher impact speed difference, higher ISS and MAIS, and higher preclinical mortality. Alcohol, 46, 681-686. DOI: 10.1016/j.alcohol.2010.07.002.

32. Waylen A.E. and McKenna, F.P. (2008) Risky attitudes towards road use in pre-drivers. Accident Analysis \& Prevention, 40(3), 905-911. DOI: 10.1016/j.aap.2007.10.005.

33. Wiebe, D.J., Ray, S., Maswabi, T., Kgathi, C. and Branas, C.C. (2016) Economic development and road traffic fatalities in two neighbouring African nations. African Journal of Emergency Medicine. 6, 80-86. DOI: 10.1016/j.afjem.2016.03.003.

34. World Health Organization (2013) WHO Global Status Report on Road Safety 2013: Supporting a Decade of Action. World Health Organization.

35. Yang, S., Lu, S. and Wu, Y. (2013) GIS-based Economic Cost Estimation of Traffic Accidents in St. Louis, Missouri. 13th COTA International Conference of Transportation Professionals (CICTP 2013). Procedia-Social and Behavioral Sciences, 96, 2907-2915. DOI: 10.1016/j.sbspro.2013.08.322. 